\title{
Vitamin D Sufficiency Status in a Sample of Egyptian Patients with Different Rheumatological Diseases Raef Malak Botros ${ }^{1}$, Amr Hassan Mostafa ${ }^{2}$, Nagwa Roshdy Mohamed ${ }^{1}$ \\ ${ }^{1}$ Department of Internal Medicine and Endocrinology, Faculty of Medicine, Ain Shams University, Cairo, Egypt. ${ }^{2}$ Department of Internal Medicine, Mabarret El-Maadi Hospital, Cairo, Egypt \\ *Corresponding author: Nagwa Roshdy Mohamed, Mobile: (+20) 01065958431, E-Mail: dr_pharos2000@yahoo.com
}

\begin{abstract}
Background: Vitamin D is a key hormone in the metabolism of calcium and phosphorus, as well as the creation and maintenance of the mineralized skeleton. It has also been linked to the etiology of autoimmune disorders such as diabetes mellitus type 1 and multiple sclerosis. Vitamin D has been the topic of several difficult investigations in recent years, including its function in the pathophysiology and development of many rheumatological disorders such as rheumatoid arthritis and systemic lupus erythematosus (SLE).

Objective: To investigate Vit D sufficiency status in different rheumatological diseases.

Patients and methods: The current study included 80 patients, divided into 20 patients with rheumatoid arthritis, 20 patients with SLE, 20 patients with osteoarthritis and 20 patients with other miscellaneous rheumatological diseases. The following investigations have been done. 25(OH) vit D, CRP, ESR, ANA, Ca, Po4, rheumatoid factor , C3,C4

Results: $60 \%$ of the studied patients had vitamin D deficiency, $33.75 \%$ had vitamin D insufficiency, $6.25 \%$ had sufficient vitamin D. Vitamin D was significantly deficient in patients with rheumatoid arthritis compared to other studied rheumatological diseases, Also vitamin D level was significantly deficient with increasing age and Longer duration of the disease ( $\mathrm{P}$ value $<0.001)$. Vitamin $\mathrm{D}$ was significantly deficient in patients on corticosteroid therapy and smoker patients.

Conclusion: $25(\mathrm{OH})$ vitamin D was significantly low in Egyptian patients with different rheumatological disease especially rheumatoid arthritis, explaining its role in development of inflammation and autoimmunity. So, 25(OH) vitamin D should be put in consideration in diagnosis and treatment of such patients.
\end{abstract}

Keywords: Vitamin D, Autoimmune disease, Rheumatoid arthritis, SLE, Osteoarthritis.

\section{INTRODUCTION}

Vitamin D is a steroid hormone that has a role in calcium and phosphorus balance. Calcium and bone metabolism are also involved (1). UV exposure stimulates the production of this hormone in the skin ${ }^{(2)}$. Vitamin $\mathrm{D}$ has an extra-skeletal impact, and insufficiency has been linked to the onset of autoimmune disorders such as type 1 diabetes and multiple sclerosis ${ }^{(3)}$. However, 1,25-dihydroxyvitamin $\mathrm{D}_{3}\left[1,25(\mathrm{OH})_{2} \mathrm{D}_{3}\right]$ the biologically active metabolite of Vitamin $D_{3}$, not only regulates bone and calcium metabolism but also exerts immunomodulation via the nuclear vitamin D receptors (VDR) expressed in antigen-presenting cells and activated $\mathrm{T} / \mathrm{B}$ cells. In particular, this regulation is mediated through interference with nuclear transcription factors such as $\mathrm{NF}-\mathrm{AT}$ and NF- $\mathrm{KB}$ or by direct interaction with vitamin $\mathrm{D}$ responsive elements in the promoter regions of cytokine genes ${ }^{(4)}$.

Epidemiological evidence suggests a link between vitamin $\mathrm{D}$ deficiency and an increased risk of autoimmune diseases, and a better understanding of the physiological role of endogenous VDR agonists in autoimmune response regulation will help justify the use of pharmacological VDR agonists in the clinic. Synthetic VDR agonists' anti-proliferative, prodifferentiative, immunomodulatory, and antiinflammatory qualities might be used to treat a number of autoimmune rheumatic disorders, from RA to SLE, as well as multiple sclerosis, type I diabetes, and inflammatory bowel illnesses ${ }^{(5)}$. Rheumatoid arthritis (RA) is an autoimmune condition with no recognised cause $^{\left({ }^{(6)}\right.}$ Vitamin D insufficiency has been linked to an increased risk of developing RA ${ }^{(7)}$.

The increased disease symptoms present in SLE patients with very low levels of vitamin $D$ suggest a role for supplementation with exogenous vitamin D to optimize therapeutic outcomes. However, the possibility that such treatment could lead to increased autoantibody levels requires further study.

\section{PATIENTS AND METHODS}

A cross sectional study was done at Rheumatology clinic of Mabarret El-Maadi Hospital, Cairo, which is a tertiary hospital, belongs to Therapeutic Foundation hospitals, Ministry of Health, Egypt. It was conducted on 80 patients during the period from September 2016 to March 2017. Patients were subdivided into 20 patients with rheumatoid arthritis diagnosed according to EULAR criteria 2016 (8), 20 patients with SLE according to Systemic Lupus International Collaborating Clinics (SLICC) criteria $2016^{(9)}, 20$ patients with osteoarthritis, and 20 patients with other miscellaneous rheumatological diseases.

Patients with any end organ disease (Chronic Liver Disease, Heart Failure or Chronic Kidney Disease), pregnant ladies and patients on vitamin D supplementation were excluded from our study. 
All the patients underwent a clinical assessment, including full history of their disease and anthropometric measures. In addition, laboratory investigations have been done including Serum 25 hydroxy vitamin $\mathrm{D}$ level by Enzyme-Linked Immunosorbent Assay (ELISA) ORG 570 KIT (manufactured by ORGENTEC Diagnostika ${ }^{\circledR}$ Germany). Vit D was interpreted as follows: Vitamin D deficient group (vitamin D level below $<20 \mathrm{ng} / \mathrm{ml}$ ), vitamin D insufficient group (vitamin D level 20-29 $\mathrm{ng} / \mathrm{ml}$ ) and vitamin D sufficient group (vitamin D level above $30 \mathrm{ng} / \mathrm{ml}$ ).

All patients were subjected to the following investigations: Serum calcium by quantitative colorimetric method, serum phosphorus by FiskeSubbarow method, serum albumin by quantitative colorimetric method and hemoglobin concentration by hemoglobincyanide method.

Erythrocyte Sedimentation Rate (ESR) by Westergren method. Creactive protein (CRP) by latex agglutination method. Uric acid by spectrophotometric and enzymatic method. Serum Creatinine, BUN by Berthelot reaction, alanine (ALT), aspartate aminotransferases (AST) by colorimetric determination, rheumatoid factor, ANA by fluorescent, anti DNA and serum C3 \& C4 by immunoturbidimetric method were also done.

\section{Ethical approval:}

The protocol of this study followed the ethical standards and approved by the Ethical Committee of our institution (Mabarret El-Maadi Hospital) and all subjects gave informed consent to participate in this study.

\section{Statistical analysis}

The collected data were revised, coded, tabulated and introduced to a PC using statistical package for social science (SPSS 20). Data were presented and suitable analysis was done according to the type of data obtained for each parameter. Parametric numerical data presented as mean $\pm \mathrm{SD}$ and range, while nonparametric numerical data were presented as median and interquartile range (IQR). Non-numerical data were presented as frequency and percentage. Student $\mathrm{T}$ test was used to assess the statistical significance of the difference between two independent groups. ChiSquare test was used to examine the relationship of two qualitative data between two independent groups. Analysis of Variance (ANOVA) was used to compare between more than two independent groups followed by post hoc analysis using TUKEY'S test, which was used for comparisons of all possible pairs of group means. Correlation analysis (using Spearman's method) was used to assess the strength of association between two quantitative variables in the same group.

The correlation coefficient denoted symbolically by " $r$ " defines the strength (magnitude) and direction (positive or negative) of the linear relationship between two variables. The confidence interval was set at $95 \%$ and the margin of error accepted was set at 5\%. A significant $\mathrm{p}$-value was considered when it is equal or less than 0.05 .

\section{RESULTS}

Table (1): Demographic data and laboratory investigations of the studied patients.

\begin{tabular}{|c|c|}
\hline No $=80$ patients & Mean \pm SD \\
\hline Age (Years) & $47.656 \pm 12.267$ \\
\hline Disease Duration (Years) & $7.881 \pm 5.321$ \\
\hline Weight (kg) & $84.075 \pm 12.927$ \\
\hline Height (cm) & $158.275 \pm 9.610$ \\
\hline BMI $\left(\mathrm{kg} / \mathrm{m}^{2}\right)$ & $33.313 \pm 6.056$ \\
\hline Serum corrected calcium $(\mathrm{mg} / \mathrm{dl})$ & $8.746 \pm 0.683$ \\
\hline S. Phosphorus (mg/dl) & $4.205 \pm 0.718$ \\
\hline S. Albumin (g/dl) & $4.155 \pm 0.505$ \\
\hline Hemoglobin (g/dl) & $12.309 \pm 1.445$ \\
\hline $\operatorname{ESR}(\mathbf{m m} / \mathbf{h})$ & $41.863 \pm 5.592$ \\
\hline S. Uric Acid (mg/dl) & $5.510 \pm 1.448$ \\
\hline Alkaline Phosphatase (IU/L) & $251.888 \pm 48.438$ \\
\hline CRP (mg/dl) & $16.663 \pm 3.467$ \\
\hline Rheumatoid Factor (IU/ml) & $44.663 \pm 6.115$ \\
\hline $25(\mathrm{OH})$ vitamin $\mathrm{D}(\mathrm{ng} / \mathrm{ml})$ & $17.538 \pm 4.938$ \\
\hline
\end{tabular}

Also, Our study showed that we had 8 male patients (10\%), 72 female patients $(90 \%), 9$ patients were smokers (11.25\%), 71 were nonsmokers (88.75), 30 patients were on corticosteroid and 50 patients were not using corticosteroids therapy. 60 patients $(75 \%)$ had positive CRP, 20 patients $(25 \%)$ had negative CRP, 24 patients (30\%) had positive rheumatoid factor and 56 patients $(70 \%)$ had negative rheumatoid factor.

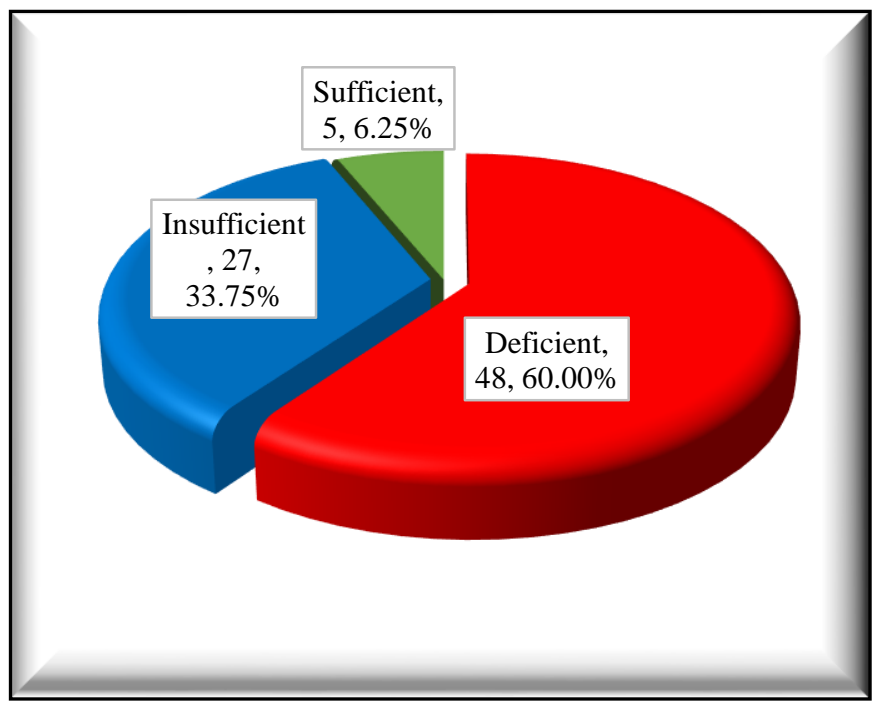

Figure (1): $25(\mathrm{OH})$ vitamin D status of the studied groups 
Table (2): Comparison of different clinical parameters with serum level of $25(\mathrm{OH})$ vitamin D

\begin{tabular}{|l|l|c|c|c|c|c|c|c|c|}
\hline \multicolumn{2}{|c|}{} & \multicolumn{2}{|c|}{ Serum 25 (OH) Vitamin D Level } & \multicolumn{2}{c|}{ ANOVA } & \multicolumn{3}{c|}{ TUKEY'S Test } \\
\hline $\begin{array}{l}\text { Age } \\
\text { (Years) }\end{array}$ & Mean \pm SD & $54.583 \pm 8.264$ & $39.852 \pm 7.789$ & $23.300 \pm 6.834$ & 53.517 & $<0.001 *$ & $<0.001 *$ & $<0.001 *$ & $<0.001 *$ \\
\hline $\begin{array}{l}\text { Disease } \\
\text { Duration } \\
\text { Years) }\end{array}$ & Mean \pm SD & $9.750 \pm 5.733$ & $5.537 \pm 2.849$ & $2.600 \pm 2.510$ & 9.845 & $<0.001 *$ & $0.001 *$ & $0.006 *$ & 0.425 \\
\hline Weight $(\mathbf{k g})$ & Mean \pm SD & $84.854 \pm 11.973$ & $82.148 \pm 14.376$ & $87.000 \pm 15.149$ & 0.509 & 0.603 & - & - & - \\
\hline Height $(\mathbf{c m})$ & Mean \pm SD & $159.917 \pm 9.531$ & $154.778 \pm 9.217$ & $161.400 \pm 8.792$ & 2.884 & 0.062 & - & - & - \\
\hline BMI (kg/m2) & Mean \pm SD & $32.958 \pm 5.903$ & $33.926 \pm 6.189$ & $33.400 \pm 7.861$ & 0.217 & 0.806 & - & - & - \\
\hline
\end{tabular}

F- ANOVA test; TUKEY's test ( $\mathrm{S}=$ Sufficient Group; I=Insufficient Group; D=Deficient Group)

P-value $\leq 0.05$ significant; $p$-value $<0.001$ highly significant; $p$-value $>0.05$ non-significant.

Table (2) showed that there was highly significant difference on comparing vitamin D status as regard age and duration of rheumatological disease revealed that vitamin $\mathrm{D}$ level was significantly deficient with increasing age and Longer duration of the disease $(\mathrm{P}$ value $<0.001)$. On the other hand, there were no significant differences between weight, height as well as BMI of the patients and vitamin D sufficiency level. ( $\mathrm{P}$ values $=0.603,0.062$ and 0.806 respectively).

Table (3): Comparison of different clinical parameters serum level of $25(\mathrm{OH})$ vitamin D

\begin{tabular}{|c|c|c|c|c|c|c|c|c|c|c|c|}
\hline & \multicolumn{8}{|c|}{ Serum $25(\mathrm{OH})$ Vitamin D Level } & \multirow{2}{*}{\multicolumn{2}{|c|}{ Chi-Square }} \\
\hline & & \multicolumn{2}{|c|}{ Deficient } & \multicolumn{2}{|c|}{ Insufficient } & \multicolumn{2}{|c|}{ Sufficient } & \multicolumn{2}{|c|}{ Total } & & \\
\hline & & $\mathbf{N}$ & $\%$ & $\mathbf{N}$ & $\%$ & $\mathbf{N}$ & $\%$ & $\mathbf{N}$ & $\%$ & $\mathbf{X}^{2}$ & P-value \\
\hline \multirow{2}{*}{ Sex } & Male & 6 & 12.50 & 2 & 7.41 & 0 & 0.00 & 8 & 10.00 & \multirow{2}{*}{1.091} & \multirow{2}{*}{0.580} \\
\hline & Female & 42 & 87.50 & 25 & 92.59 & 5 & 100.00 & 72 & 90.00 & & \\
\hline \multirow{2}{*}{ Smoking } & Yes & 9 & 18.75 & 0 & 0.00 & 0 & 0.00 & 9 & 11.25 & \multirow{2}{*}{6.761} & \multirow{2}{*}{$0.034^{*}$} \\
\hline & No & 39 & 81.25 & 27 & 100.00 & 5 & 100.00 & 71 & 88.75 & & \\
\hline \multirow{2}{*}{$\begin{array}{l}\text { Corticosteroid } \\
\text { Therapy }\end{array}$} & Yes & 25 & 52.08 & 5 & 18.52 & 0 & 0.00 & 30 & 37.50 & \multirow{2}{*}{11.506} & \multirow{2}{*}{$0.003^{*}$} \\
\hline & No & 23 & 47.92 & 22 & 81.48 & 5 & 100.00 & 50 & 62.50 & & \\
\hline \multirow{4}{*}{$\begin{array}{l}\text { Rheumatological } \\
\text { Diseases }\end{array}$} & Osteoarthritis & 9 & 18.75 & 8 & 29.63 & 3 & 60.00 & 20 & 25.00 & \multirow{4}{*}{13.863} & \multirow{4}{*}{$0.031 *$} \\
\hline & $\begin{array}{l}\text { Rheumatoid } \\
\text { Arthritis }\end{array}$ & 17 & 35.42 & 3 & 11.11 & 0 & 0.00 & 20 & 25.00 & & \\
\hline & Systemic lupus & 14 & 29.17 & 6 & 22.22 & 0 & 0.00 & 20 & 25.00 & & \\
\hline & Miscellaneous & 8 & 16.67 & 10 & 37.04 & 2 & 40.00 & 20 & 25.00 & & \\
\hline
\end{tabular}

$\mathrm{X}^{2}$ - Chi-square test, $\mathrm{N}=$ Number $\quad \mathrm{p}$-value $\leq 0.05$ significant; $\mathrm{p}$-value $<0.001$ highly significant; $\mathrm{p}$-value $>0.05$ non-significant

Table (3) showed that there was statistically significant differences on comparing vitamin D sufficiency status regarding smoking, corticosteroid therapy and rheumatological diseases. Vitamin D level was significantly deficient in smoker patients compared to non-smoker patients. Patients received corticosteroid therapy had significant vitamin D deficiency (From the 30 patients who received corticosteroid therapy, 25 patients were in the deficient group and 5 patients were in the insufficient group) compared to others did not receive ( $\mathrm{P}$ value $<0.05)$. As regards studied rheumatological diseases, patients with rheumatoid arthritis had significant vitamin D deficiency compared to patients with SLE and miscellaneous diseases, than insufficient vitamin D level (P value $<0.05)$. 
Table (4): Comparison of different lab parameters with serum level of $25(\mathrm{OH})$ vitamin D

\begin{tabular}{|l|c|c|c|c|c|c|c|c|c|}
\hline \multicolumn{2}{|c}{} & \multicolumn{2}{|c|}{ Serum 25 (OH) Vitamin D Level } & \multicolumn{2}{c|}{ ANOVA } & \multicolumn{3}{c|}{ TUKEY'S Test } \\
\cline { 3 - 9 } & Deficient & Insufficient & Sufficient & F & P-value & D\&I & D\&S & I\&S \\
\hline $\begin{array}{l}\text { Calcium } \\
\text { (mg/dl) }\end{array}$ & Mean \pm SD & $8.408 \pm 0.552$ & $9.100 \pm 0.426$ & $10.080 \pm 0.084$ & 35.816 & $<0.001 *$ & $<0.001 *$ & $<0.001 *$ & $<0.001 *$ \\
\hline $\begin{array}{l}\text { Phosphorus } \\
\text { (mg/dl) }\end{array}$ & Mean \pm SD & $3.850 \pm 0.502$ & $4.533 \pm 0.464$ & $5.840 \pm 0.483$ & 46.829 & $<0.001 *$ & $<0.001 *$ & $<0.001 *$ & $<0.001 *$ \\
\hline $\begin{array}{l}\text { Albumin } \\
\text { (g/dl) }\end{array}$ & Mean \pm SD & $4.200 \pm 0.488$ & $4.107 \pm 0.576$ & $3.986 \pm 0.120$ & 0.583 & 0.560 & - & - & - \\
$\begin{array}{l}\text { Hemoglobin } \\
\text { (g/dl) }\end{array}$ & Mean \pm SD & $12.156 \pm 1.543$ & $12.456 \pm 1.343$ & $12.980 \pm 0.719$ & 0.945 & 0.393 & - & - & - \\
\hline $\begin{array}{l}\text { ESR } \\
\text { (mm/h) }\end{array}$ & Mean \pm SD & $54.125 \pm 5.379$ & $25.852 \pm 4.611$ & $10.600 \pm 3.209$ & 22.389 & $<0.001 *$ & $<0.001 *$ & $<0.001 *$ & 0.287 \\
\hline $\begin{array}{l}\text { Uric Acid } \\
\text { (mg/dl) }\end{array}$ & Mean \pm SD & $6.458 \pm 1.734$ & $4.237 \pm 0.636$ & $3.280 \pm 0.084$ & 11.896 & $<0.001 *$ & $<0.001 *$ & $0.007 *$ & 0.638 \\
\hline $\begin{array}{l}\text { Alkaline } \\
\text { Phosphatase } \\
\text { (IU/L) }\end{array}$ & Mean \pm SD & $248.896 \pm 48.654$ & $244.407 \pm 45.668$ & $321.000 \pm 76.464$ & 0.580 & 0.562 & - & - & - \\
\hline
\end{tabular}

F- ANOVA test; TUKEY's test (S=Sufficient Group; I=Insufficient Group; D=Deficient Group) $\quad$-value $<0.05$ significant ; $p$ value $<0.001$ highly significant; $p$-value $\leq 0.05$ non-significant

Table (4) showed that there were highly significant differences on comparing different vitamin D statuses with serum calcium level, serum phosphorus level, ESR and uric acid showing that vitamin D deficiency associated with significant low serum calcium and phosphorus $(\mathrm{P}$ value $<0.001)$.

Table (5): Comparison between Serum $25(\mathrm{OH})$ vitamin D levels with CRP and rheumatoid factor

\begin{tabular}{|c|c|c|c|c|c|c|c|c|c|}
\hline & \multicolumn{3}{|c|}{ Serum $25(\mathrm{OH})$ Vitamin D Level } & \multicolumn{2}{|c|}{ ANOVA } & \multicolumn{3}{|c|}{ TUKEY'S Test } \\
\hline & & Deficient & Insufficient & Sufficient & $\mathbf{F}$ & P-value & D\&I & D\&S & I\&S \\
\hline$P$ & & $22.792 \pm 4.327$ & $8.667 \pm 1.452$ & $1.000 \pm 0.001$ & 8.791 & $<0.001^{*}$ & $<0.001 *$ & $<0.001 *$ & $0.015 *$ \\
\hline $\begin{array}{l}\text { Rheumatoid Fact } \\
\text { (IU/ml) }\end{array}$ & Mean \pm & $729 \pm 9.851$ & $7.519 \pm 1$ & $4.600 \pm 0$. & 12.662 & $<0.00$ & $<0.001 *$ & $0.035^{*}$ & 0.9 \\
\hline
\end{tabular}

F- ANOVA test; TUKEY's test (S=Sufficient Group; I=Insufficient Group; D=Deficient Group) $\quad$-value $\leq 0.05$ significant; $p$ value $<0.001$ highly significant; $p$-value $>0.05$ no significant

Table (5) showed that significant lower vitamin D associated with high CRP and rheumatoid factor compared to other vitamin $\mathrm{D}$ statuses $(\mathrm{P}$ value $<0.001)$.

Table (6): Correlations of different clinical and lab parameters with serum $25(\mathrm{OH})$ vitamin D

\begin{tabular}{|l|c|c|}
\hline \multirow{2}{*}{} & \multicolumn{2}{|c|}{$\mathbf{2 5}(\mathbf{O H})$ Vitamin D (ng/ml) } \\
\cline { 2 - 3 } Age & $\mathbf{r}$ & P-value \\
\hline Disease Duration (Years) & -0.859 & $<0.001^{*}$ \\
\hline Weight (kg) & -0.534 & $<0.001^{*}$ \\
\hline Height (cm) & -0.114 & 0.314 \\
\hline BMI (kg/m2) & -0.113 & 0.316 \\
\hline Calcium (mg/dl) & -0.016 & 0.890 \\
\hline Phosphorus (mg/dl) & 0.792 & $<0.001^{*}$ \\
\hline Albumin (g/dl) & 0.785 & $<0.001^{*}$ \\
\hline Hemoglobin (g/dl) & -0.118 & 0.298 \\
\hline ESR & 0.114 & 0.315 \\
\hline Uric Acid (mg/dl) & -0.653 & $<0.001^{*}$ \\
\hline Alkaline Phosphatase (IU/L) & -0.682 & $<0.001^{*}$ \\
\hline CRP (mg/dl) & 0.211 & 0.060 \\
\hline Rheumatoid Factor (IU/ml) & -0.946 & $<0.001^{*}$ \\
\hline
\end{tabular}

r- Pearson Correlation Coefficient $\quad$-value $<0.05$ significant; $p$-value $<0.001$ highly significant; $p$-value $>0.05$ non-significant

Table (6) showed that there were highly significant negative correlations among vitamin D level, age, disease duration, ESR, uric acid, CRP, and rheumatoid factor $(\mathrm{P}$ value $<0.001)$. On the other hand, there were highly significant positive correlation between vitamin $\mathrm{D}$, serum calcium and phosphorus levels $(\mathrm{P}$ value $<0.001)$. 


\section{DISCUSSION}

Our results showed significant reduction of serum $25(\mathrm{OH})$ vitamin $\mathrm{D}$ in smoker patients in addition to patients who received corticosteroid therapy $\mathrm{P}$ value $<0.05$. In spite, the fact that smoke and vitamin $\mathrm{D}$ both have a role in producing and relieving inflammation, little study has been done on how smoke affects vitamin D levels and their capacity to operate in the respiratory system. According to findings published in the Journal of Allergy and Clinical Immunology, cigarette smoke is linked to lower vitamin D levels as well as a reduced capacity to activate vitamin D in nasal cells ${ }^{(\mathbf{1 0})}$. Our results agree with a cross-sectional study done by Supervia $\boldsymbol{e t} \boldsymbol{a l}$. (11) who showed that smoker volunteers had lower serum $25(\mathrm{OH})$ vitamin D levels

Our study showed that patients on corticosteroid therapy had significant vitamin D deficiency. This agrees with Briot and Roux ${ }^{(12)}$ who found that glucocorticoids intake was independently and inversely associated with low vitamin D levels

Our study showed that serum vitamin D was at the lowest level in patients with rheumatoid arthritis followed by SLE, osteoarthritis and miscellaneous diseases respectively ( $\mathrm{P}$ value $<0.05$ ). Moreover, there were highly significant differences as regards CRP and rheumatoid factor level and vitamin D status levels. Our results go hand in hand with Hajjaj-Hassouni $\boldsymbol{e t}$ al. ${ }^{(13)}$ who studied vitamin D status in rheumatoid arthritis and its association with disease activity across 15 countries. They reported that status of vitamin D was insufficient in $54.6 \%$ and deficient in $8.5 \%$ of patients. Also, the study showed that the status of low levels of vitamin D was common in RA in different countries and under different latitudes. Low levels of vitamin D were associated with patients' age, RA (disease activity and corticosteroid dosage) ( $<$ < 0.001).

The link between SLE and vitamin D insufficiency has been discovered in a number of investigations. Vitamin D insufficiency causes the immune system to respond in a way that leads to tolerance loss. Vitamin D supplementation reverses immunological abnormalities associated with SLE in vitro ${ }^{(14)}$. A cohort study by Kamen et al. ${ }^{(15)}$ of 123 recently diagnosed SLE patients and 240 controls were used. The study showed that a lower $25(\mathrm{OH}) \mathrm{D}$ levels in SLE cases compared to controls was statistically significant in Caucasians $(\mathrm{P}=0.04)$. Overall, $67 \%$ of the subjects were vitamin $\mathrm{D}$ deficient, with mean levels significantly lower among African Americans $(15.9 \mathrm{ng} / \mathrm{ml})$ compared to Caucasians $(31.3 \mathrm{ng} / \mathrm{ml})$. Critically low vitamin D levels $(<10 \mathrm{ng} / \mathrm{ml})$ were found in 22 of the SLE cases with renal disease.

Our study showed that increase in age was associated with significant vitamin D deficiency this agrees with Gallagher ${ }^{\mathbf{( 1 6 )}}$ who found that aging affects the formation of 1,25-dihydroxyvitamin $\mathrm{D}$ by about $50 \%$ reduction as result of decline of renal function.

Our study showed that there were highly significant differences as regards duration of the disease and serum $25(\mathrm{OH})$ vitamin D sufficiency. Serum $25(\mathrm{OH})$ vitamin D level decreased with disease duration increase. This comes in agreement with Lopes $\boldsymbol{e t}$ al. ${ }^{(17)}$ who studied the association of vitamin D status with rheumatoid arthritis disease activity and UV index and concluded that vitamin D levels decrease with disease duration increase.

In our study, there were highly significant negative correlations between serum $25(\mathrm{OH})$ vitamin D level and ESR, uric acid, CRP and rheumatoid factor ( $\mathrm{P}$ value $<0.001)$. This agrees with Almerighi et al. (18) who studied the association between levels of vitamin $\mathrm{D}$ and inflammatory markers and reported that vitamin D had a strong relation with inflammatory markers, which revealed the immunomodulatory action of vitamin $\mathrm{D}$ on the immune system.

In the present study, there were highly significant positive correlations between serum $25(\mathrm{OH})$ vitamin D level with both serum calcium and phosphorus levels (P value $<0.001)$. This agrees with Need et al. ${ }^{\left({ }^{(19)}\right.}$ who studied vitamin D metabolites and calcium absorption in vitamin D deficiency, which revealed that calcium absorption in addition to serum calcium were significantly decreased in cases with $25(\mathrm{OH})$ vitamin D deficiency.

\section{CONCLUSION}

The present study showed that $25(\mathrm{OH})$ vitamin D deficiency was found in Egyptian patients with rheumatological disease especially in rheumatoid arthritis where they had lower level of vitamin D compared to other rheumatological disease. This explains the role of vitamin D deficiency in inflammation and autoimmunity. So, $25(\mathrm{OH})$ vitamin $\mathrm{D}$ should be put in consideration in diagnosis and treatment of such patients.

\section{REFERENCES}

1. Holick M (2011): Vitamin D: evolutionary, physiological and health perspectives. Curr Drug Targets, 12: 4-18.

2. Mason R, Sequeira V, Gordon-Thomson C (2011): Vitamin D: the light side of sunshine. Eur J Clin Nutr., 65: 986-993

3. Jankosky C, Deussing E, Gibson R et al. (2012): Viruses and vitamin $D$ in the etiology of type 1 diabetes mellitus and multiple sclerosis. Virus Res., 163: 424-430.

4. van Etten E, Mathieu C (2005): Immunoregulation by 1,25-dihydroxyvitamin D3: basic concepts. J Steroid Biochem Mol Biol., 97: 93-101.

5. Adorini A, Penna G (2007): Control of autoimmune diseases by the vitamin D endocrine system. Nat Clin Pract Rheumatol., 4: 404-12. 
6. McInnes I, Schett, G (2011): The pathogenesis of rheumatoid arthritis. N Engl J Med., 365: 2205-2219.

7. Merlino L Curtis J, Mikuls T et al. (2004): Iowa Women's Health Study,Vitamin D intake is inversely associated with rheumatoid arthritis: results from the Iowa Women's Health Study. Arthritis Rheum., 50: 72-77.

8. Shiboski C, Shiboski S, Seror R et al. (2017): 2016 American College of Rheumatology/European League Against Rheumatism classification criteria for primary Sjögren's syndrome: a consensus and data-driven methodology involving three international patient cohorts. Ann Rheum Dis., 76 (1): 9-16.

9. Tiao J, Feng R, Carr K et al. (2016): Using the American College of Rheumatology and Systemic Lupus International Collaborating Clinics Criteria to determine the diagnosis of systemic lupus erythematosus in patients with subacute cutaneous lupus erythematosus. J Am Acad Dermatol., 74: 8629.

10. Mulligan J, Nagel W, O'Connell B et al. (2014): Cigarette smoke exposure is associated with vitamin D3 deficiencies in patients with chronic rhinosinusitis. The Journal of Allergy and Clinical Immunology, 134: 342-49

11. Supervía $X$, Nogués A, Enjuanes J et al. (2006): Effect of smoking and smoking cessation on bone mass, bone remodeling, vitamin D, PTH and sex hormones. Journal of Musculoskeletal and Neuronal Interactions, 6: 234-41.
12. Briot K, Roux C (2015): Glucocorticoid-induced osteoporosis. British Medical Journal, 1: 20-29.

13. Hajjaj-Hassouni $\mathrm{N}$, Mawani $\mathrm{N}$, Allali $\mathrm{F}$ et al. (2017): Evaluation of Vitamin D Status in Rheumatoid Arthritis and Its Association with Disease Activity across 15 Countries: "The COMORA Study". International Journal of Rheumatology, 5: 117-21.

14. Cutolo M, Otsa K (2008): Review: vitamin D, immunity and lupus. Lupus, 17:6-10.

15. Kamen D, Cooper G, Bouali H et al. (2006): Vitamin $\mathrm{D}$ deficiency in systemic lupus erythematosus. Autoimmunity Reviews, 5: 114-17.

16. Gallagher J (2013): Vitamin D and Aging. Endocrinology and Metabolism Clinics of North America, 42: 319-32.

17. Lopes V, Lopes J, Brasileiro J et al. (2017): Highly prevalence of vitamin D deficiency among Brazilian women of reproductive age. Archives of Endocrinology and Metabolism, 61: 21-27

18. Almerighi C, Cavazza A, Ciaprini C et al. (2009): 1 Alpha, 25-dihydroxyvitamin D3 inhibits CD40Linduced proinflammatory and immunomodulatory activity in human monocytes. Cytokine, International Journal of Current Microbiology And Applied Sciences, 45: 190-97.

19. Need A, O'Loughlin P, Morris H et al. (2008): Vitamin D metabolites and calcium absorption in severe vitamin D deficiency. Journal of Bone and Mineral Research, 23: 1859-63. 